\title{
Impact of self-reported physical activity and health promotion behaviors on lung cancer survivorship
}

\author{
Jeff A. Sloan ${ }^{1 *}$, Andrea L. Cheville², Heshan Liu', Paul J. Novotny', Jason A. Wampfler', Yolanda I. Garces ${ }^{3}$,
} Matthew M. Clark ${ }^{4}$ and Ping Yang ${ }^{1}$

\begin{abstract}
Background: There is some initial evidence that an enhanced physical activity level can improve fquality of life, and possibly survival among patients with lung cancer. The primary aim of this project was to evaluate the impact of physical activity on the quality and quantity of life of lung cancer survivors.

Methods: Between January 1, 1997, and December 31, 2009, a total of 1466 lung cancer survivors completed a questionnaire with patient-reported outcomes for quality of life (QOL), demographics, disease and clinical characteristics, and a measure of physical activity (Baecke Questionnaire). Chi-square tests compared lung cancer survivors who reported being physically active versus not on a variety of the other covariates. Kaplan-Meier estimates and Cox models evaluated the prognostic importance of physical activity level on Overall Survival (OS).

Results: Roughly half of the lung cancer survivors had advanced stage disease at the time of survey. Treatment prevalence rates were 61,54 , and $33 \%$ for surgery, chemotherapy and radiotherapy, respectively. The majority (77\%) of survivors reported themselves as physically active. Physically active survivors reported greater activity across all individual Baecke items. Lung cancer survivor-reported QOL indicated the benefits of physical activity in all domains. Survivors receiving chemotherapy or radiation at the time of questionnaire completion were less likely to be physically active (74 and $73 \%$ respectively). In contrast, $84 \%$ of surgical patients were physically active. Disease recurrence rates were the same for physically active and inactive patients ( $81 \%$ vs $82 \%, p=0.62$ ). Physically active patients survived an average of 4 more years than those who were not physically active (8.4 years versus 4.4 years respectively, log rank $p<0.0001$ ).
\end{abstract}

Conclusions: Being physically active was related to profound advantages in QOL and survival in a large sample of lung cancer survivors.

\section{Background}

There is some initial evidence that an enhanced physical activity level can improve feelings of well-being, quality of life, and possibly survival among patients with lung cancer [1]. In general the impact of exercise behaviors following a cancer diagnoses has been most extensively investigated for patients with breast and gastrointestinal malignancies $[2,3]$. However, accruing evidence suggests that exercise behaviors may be an important and actionable determinant of lung cancer outcomes. The potential

\footnotetext{
* Correspondence: jsloan@mayo.edu

'Department of Health Sciences Research, 200 First St SW, Rochester, MN 55905, USA

Full list of author information is available at the end of the article
}

for a novel, non-toxic therapy warrants attention, since lung cancer, the most common cause of cancer death, has a tendency for late-stage diagnosis and, despite novel drug therapies, rapid, morbid, and inexorable progression [4].

To date a range of both cross-sectional and longitudinal studies have examined associations between aerobic fitness and important outcomes at seminal points along the lung cancer trajectory. With few exceptions, investigators have characterized aerobic fitness at a single time point using maximal oxidative capacity $\left(\mathrm{VO}_{2 \max }\right)$ or 6 min walk distance (6MWD). Cross sectional investigations have shown that aerobic fitness is associated with post-operative symptom burden and quality of life among patients with operable lung cancer $[5,6]$. 
Longitudinal investigations have demonstrated that aerobic fitness predicts peri-operative complication rates for lung cancer surgeries, [7-9] as well as overall survival for both operable [1] and inoperable [10] lung cancer. Encouragingly, pilot studies have found exercisebased pulmonary rehabilitation programs, both pre- and post-operative, to be well tolerated and to enhance aerobic fitness [9, 11-13]. Even patients with late stage lung cancer derive benefit from exercise training as manifest in improved a functional capacity and a reduced symptom burden [14-16].

Despite mounting evidence attesting the benefits of enhanced physical activity among lung cancer survivors, the longitudinal impact of shifting activity levels following a lung cancer diagnosis has yet to be examined using repeated measures. Our group previously reported that endorsement of regular physical activity among 272 long-term lung cancer survivors was associated with higher scores in overall QOL and all QOL sub-domains, as well as a reduced symptom burden [26]. The primary aim of this project was to prospectively examine the relationship of physical activity level with quality of life and overall survival across multiple time points in a larger cohort of 1466 long-term lung cancer survivors. Secondary aims included examining the influence of treatment and demographic variables on these relationships and describing differences between survivors who did and did not characterize themselves as being physically active.

\section{Methods}

The Mayo Clinic Epidemiology and Genetics of Lung Cancer Research Program has enrolled and prospectively followed patients either diagnosed with and/or treated for lung cancer at Mayo Clinic, Rochester, Minnesota since its inception in 1997. Between January 1, 1997, and December 31, 2009, over 10,000 patients have been enrolled. Procedures for identifying and following lung cancer patients enrolled in this program have been previously described [17]. Patient follow-up was accomplished by mailed questionnaire beginning at six months after diagnosis and annually thereafter.

Quality of life was assessed at all follow-up time points by means of one item from the Lung Cancer Symptom Scale (LCSS) $[18,19]$. The overall QOL item served as the primary endpoint in the current study. In the primary analysis overall QOL is considered as a continuous variable, taking integer values from 0 to 100 . Previously, The North Central Cancer treatment Group (NCCTG) Lung Cancer Committee compared alternative QOL assessments (the European Organization for the Research and Treatment of Cancer Quality of Life Questionnaire and Lung Cancer Module(EORTC-QLQ-LC13), the Functional Assessment of Cancer Therapy - Lung
(FACT-L), and the Lung Cancer Symptom Scale(LCSS)) using a series of phase II clinical trials (NCCTG trials 95-20-53, 95-24-52, 96-24-51, 98-24-52). Ultimately it was found that the LCSS performed as well as the other two assessments and used fewer items to obtain the same information [20]. A pooled analysis of lung cancer studies indicated that the single-item QOL assessments developed within the NCCTG were more sensitive to change than longer, multi-item assessments [21]. This study also demonstrated that the relationship between QOL assessments and toxicity was modest at best and that clinically meaningful changes in QOL preceded adverse events captured by the Common Toxicity Criteria(CTC) by two to three months.

These single-item assessments have become the mostused assessment in all NCI-sponsored cancer control studies [22] and have been validated extensively against more involved assessment processes [23, 24]. Normative data have been obtained from various clinical populations enrolled in NCCTG clinical trials and from healthy participants attending an NCCTG annual meeting. In assessing overall QOL on a $0-100$ point scale, healthy volunteers will average about 82 , hospice patients will average 78 , advanced cancer patients will average somewhere between 60 and 75, newly diagnosed patients will average between 50 and 60 . A score of 50 or below is indicative of a need for immediate exploration and intervention for the QOL deficit [25]. This cutoff has been validated both by our research team [21, 26] and independently by others [27-29]. We recently published data indicating that these measures held prognostic power specifically among lung cancer patients [30]. The NCCTG has included Linear Analog Scale Assessmen$\mathrm{t}$ (LASA) measures for overall QOL and fatigue in all phase II and phase III clinical trials since 2009 as an independent prognostic factor independent of performance status.

Self-reported physical activity and health promotion behaviors were provided by the lung cancer survivors using the modified Baecke questionnaire for physical activity [31]. First developed for epidemiological studies of physical activity in a Dutch population [32], the 16-item questionnaire consists of three subscales: 1) physical activity at work; 2) sport during leisure time; and 3) physical activity during leisure time excluding sport [33]. It has been used in healthy, elderly, and chronic fatigue populations successfully [34-36]. Recent studies have idenitifed issues with its validity and reliability, but it remains the most often-used questionnaire for assessing physical activity in epidemiological studies [37]. Specifically, it has been suggested that the Baecke questionnaire is best used to differentiate between active and inactive individuals rather 
Table 1 Participant characteristics for 1466 lung cancer survivors by Baecke physical activity data

\begin{tabular}{|c|c|c|c|}
\hline Participant characteristic & Non-physically active $(N=331)$ & Physically active $(N=1135)$ & Total $(N=1466)$ \\
\hline \multicolumn{4}{|l|}{ Age at diagnosis } \\
\hline N & 331 & 1135 & 1466 \\
\hline Mean (SD) & $68.7(9.73)$ & $64.9(10.82)$ & $65.7(10.7)$ \\
\hline Range & $(35.0-91.0)$ & $(18.0-93.0)$ & $(18-93)$ \\
\hline \multicolumn{4}{|l|}{ Gender } \\
\hline Female & $158(47.7 \%)$ & $568(50 \%)$ & $726(49.5 \%)$ \\
\hline Male & $173(52.3 \%)$ & $567(50 \%)$ & $740(50.5 \%)$ \\
\hline \multicolumn{4}{|l|}{ Race } \\
\hline Caucasian & $311(94 \%)$ & 1059 (93.3 \%) & 1370 (93.5 \%) \\
\hline Hispanic & $4(1.2 \%)$ & $8(0.7 \%)$ & $12(0.8 \%)$ \\
\hline Alaskan/Indian & $15(4.5 \%)$ & $54(4.8 \%)$ & $69(4.7 \%)$ \\
\hline Black & $1(0.3 \%)$ & $3(0.3 \%)$ & $4(0.3 \%)$ \\
\hline Asian/Pacific Islander & $0(0.0 \%)$ & $6(0.5 \%)$ & $6(0.4 \%)$ \\
\hline Unknown & $0(0.0 \%)$ & $5(0.4 \%)$ & $5(0.3 \%)$ \\
\hline \multicolumn{4}{|c|}{ Years of schooling completed } \\
\hline $\mathrm{N}$ & 67 & 307 & 374 \\
\hline Mean (SD) & $13.0(2.35)$ & $13.6(2.41)$ & $13.5(2.4)$ \\
\hline Range & $(6.0-17.0)$ & $(5.0-18.0)$ & $(5.0-18.0)$ \\
\hline \multicolumn{4}{|l|}{ Marital status } \\
\hline Missing & 62 & 185 & 247 \\
\hline Single & 9 (3.3\%) & $47(4.9 \%)$ & $56(4.6 \%)$ \\
\hline Married & 194 (72.1 \%) & $751(79.1 \%)$ & $945(77.5 \%)$ \\
\hline Divorced & $27(10 \%)$ & $75(7.9 \%)$ & $102(8.4 \%)$ \\
\hline Widowed & 39 (14.5\%) & $75(7.9 \%)$ & $114(9.4 \%)$ \\
\hline Life partner & $0(0.0 \%)$ & $2(0.2 \%)$ & $2(0.2 \%)$ \\
\hline \multicolumn{4}{|l|}{ Vital status (as of 2/2010) } \\
\hline Alive & $167(50.5 \%)$ & $787(69.3 \%)$ & 954 (65.1\%) \\
\hline Dead & $164(49.5 \%)$ & $348(30.7 \%)$ & $512(34.9 \%)$ \\
\hline \multicolumn{4}{|c|}{ Time to last FU (as of $2 / 2010$ ) in years } \\
\hline $\mathrm{N}$ & 331 & 1135 & 1466 \\
\hline Mean (SD) & $2.7(2.15)$ & $3.3(2.43)$ & $3.1(2.38)$ \\
\hline Range & $(0.1-8.6)$ & $(0.0-9.0)$ & 2.2 \\
\hline \multicolumn{4}{|l|}{ Cigarette smoking status } \\
\hline Never & 36 (10.9\%) & $218(19.2 \%)$ & $254(17.3 \%)$ \\
\hline Former smoker & $165(49.8 \%)$ & $615(54.2 \%)$ & $780(53.2 \%)$ \\
\hline Current smoker & 129 (39\%) & $294(25.9 \%)$ & $423(28.9 \%)$ \\
\hline Some smoking history & $1(0.3 \%)$ & $8(0.7 \%)$ & $9(0.6 \%)$ \\
\hline \multicolumn{4}{|l|}{ Pack-Years } \\
\hline N & 292 & 910 & 1202 \\
\hline Mean (SD) & $53.2(34.44)$ & $45.4(28.29)$ & $47.3(30.07)$ \\
\hline Range & $(0.5-208.0)$ & $(0.0-180.0)$ & $(0.0-208.0)$ \\
\hline \multicolumn{4}{|l|}{ Condensed grade } \\
\hline Missing & 1 & 6 & 7 \\
\hline $1=$ Well differentiated & $58(17.6 \%)$ & $328(29.1 \%)$ & $386(26.5 \%)$ \\
\hline
\end{tabular}


Table 1 Participant characteristics for 1466 lung cancer survivors by Baecke physical activity data (Continued)

\begin{tabular}{|c|c|c|c|}
\hline $2=$ Moderately differentiated & $104(31.5 \%)$ & $414(36.7 \%)$ & $518(35.5 \%)$ \\
\hline 3 = Poorly differentiated & $142(43 \%)$ & $321(28.4 \%)$ & $463(31.7 \%)$ \\
\hline $4=$ Non-gradeable & $26(7.9 \%)$ & $66(5.8 \%)$ & $92(6.3 \%)$ \\
\hline \multicolumn{4}{|l|}{ Stage } \\
\hline Missing & 6 & 5 & 11 \\
\hline Limited & $27(8.3 \%)$ & $36(3.2 \%)$ & $63(4.3 \%)$ \\
\hline Extensive & $22(6.8 \%)$ & $30(2.7 \%)$ & $52(3.6 \%)$ \\
\hline Stage IA & 49 (15.1\%) & $320(28.3 \%)$ & $369(25.4 \%)$ \\
\hline Stage IB & $48(14.8 \%)$ & $186(16.5 \%)$ & $234(16.1 \%)$ \\
\hline Stage IIA & $6(1.8 \%)$ & $24(2.1 \%)$ & $30(2.1 \%)$ \\
\hline Stage IIB & $17(5.2 \%)$ & $68(6 \%)$ & $85(5.8 \%)$ \\
\hline Stage IIIA & $42(12.9 \%)$ & $124(11 \%)$ & $166(11.4 \%)$ \\
\hline Stage IIIB & $45(13.8 \%)$ & $116(10.3 \%)$ & $161(11.1 \%)$ \\
\hline Stage IV & $69(21.2 \%)$ & $226(20 \%)$ & $295(20.3 \%)$ \\
\hline \multicolumn{4}{|l|}{ T (tumor) of TNM staging } \\
\hline Missing & 69 & 176 & 245 \\
\hline No primary tumor & $6(2.3 \%)$ & $10(1.0 \%)$ & $16(1.3 \%)$ \\
\hline Tumor $<=3 \mathrm{~cm}$ & $83(31.7 \%)$ & $420(43.8 \%)$ & $503(41.2 \%)$ \\
\hline Tumor $>3 \mathrm{~cm}$ & $92(35.1 \%)$ & $309(32.2 \%)$ & $401(32.8 \%)$ \\
\hline Invades chest wall & $14(5.3 \%)$ & $54(5.6 \%)$ & $68(5.6 \%)$ \\
\hline Invades mediastinum & $56(21.4 \%)$ & $137(14.3 \%)$ & $193(15.8 \%)$ \\
\hline Cannot be assessed & $11(4.2 \%)$ & $29(3 \%)$ & $40(3.3 \%)$ \\
\hline \multicolumn{4}{|l|}{$N$ (nodes) of TNM staging } \\
\hline Missing & 51 & 123 & 174 \\
\hline No nodal mets & $122(43.6 \%)$ & $611(60.4 \%)$ & $733(56.7 \%)$ \\
\hline In Peribr/Hilar & $30(10.7 \%)$ & $98(9.7 \%)$ & $128(9.9 \%)$ \\
\hline In Medias/Subcarinal & $97(34.6 \%)$ & $210(20.8 \%)$ & $307(23.8 \%)$ \\
\hline Mets in contralaterl & $22(7.9 \%)$ & $76(7.5 \%)$ & 98 (7.6 \%) \\
\hline Nodes Unassessable & $9(3.2 \%)$ & $17(1.7 \%)$ & $26(2 \%)$ \\
\hline \multicolumn{4}{|l|}{ Surgery } \\
\hline Missing & 12 & 27 & 39 \\
\hline No & 179 (56.1%) & $381(34.4 \%)$ & $560(39.2 \%)$ \\
\hline Yes & 140 (43.9 \%) & $727(65.6 \%)$ & $867(60.8 \%)$ \\
\hline \multicolumn{4}{|l|}{ Surgery within 6 months } \\
\hline Missing & 12 & 27 & 39 \\
\hline No & $189(59.2 \%)$ & $435(39.3 \%)$ & $624(43.7 \%)$ \\
\hline Yes & $130(40.8 \%)$ & $673(60.7 \%)$ & $803(56.3 \%)$ \\
\hline \multicolumn{4}{|l|}{ Chemotherapy } \\
\hline Missing & 12 & 27 & 39 \\
\hline No & 120 (37.6 \%) & $542(48.9 \%)$ & $662(46.4 \%)$ \\
\hline Yes & 199 (62.4 \%) & $566(51.1 \%)$ & $765(53.6 \%)$ \\
\hline \multicolumn{4}{|l|}{ Chemotherapy within 6 months } \\
\hline Missing & 12 & 27 & 39 \\
\hline No & $166(52 \%)$ & $686(61.9 \%)$ & $852(59.7 \%)$ \\
\hline Yes & $153(48 \%)$ & $422(38.1 \%)$ & $575(40.3 \%)$ \\
\hline
\end{tabular}


Table 1 Participant characteristics for 1466 lung cancer survivors by Baecke physical activity data (Continued)

\begin{tabular}{|c|c|c|c|}
\hline \multicolumn{4}{|l|}{ Radiation } \\
\hline Missing & 12 & 27 & 39 \\
\hline No & $193(60.5 \%)$ & $769(69.4 \%)$ & $962(67.4 \%)$ \\
\hline Yes & $126(39.5 \%)$ & $339(30.6 \%)$ & 465 (32.6 \%) \\
\hline \multicolumn{4}{|c|}{ Radiation within 6 months } \\
\hline Missing & 12 & 27 & 39 \\
\hline No & $230(72.1 \%)$ & 875 (79 \%) & $1105(77.4 \%)$ \\
\hline Yes & 89 (27.9\%) & $233(21 \%)$ & $322(22.6 \%)$ \\
\hline
\end{tabular}

than to differentiate active people into low and high activity level categories [38].

The study sample included 1466 lung cancer survivors who completed the Baecke questionnaire at least once. The study sample used the first Baecke data recorded by each survivor to define the participant's physical activity level. We found little change over time in the Baecke scores (data not shown). By using the first observed Baecke scores, we acknowledge that the time since diagnosis and years studied will be variable. The scoring algorithm for the Baecke questionnaire was untenable because of a large amount of non-interpretable data. Our study team went through an extensive data cleaning operation wherein we made operational definitions and decisions as to how to record various eccentricities in the data. For example, patients provided multiple sports when asked for their primary sport activity, reported gambling as a sport, or provided Illogical combinations such as indicating they engaged in physical exercise during leisure time regularly for a total of zero minutes per day. As a result it became clear that we would only be able to present some subscale data and in reality could only analyze individual questions with confidence. The study protocol was reviewed and approved by the Mayo Clinic Institutional Review Board. Ethics approval of this study was granted by Mayo Clinic Institutional Review Board. Written informed consent was obtained from all participants.

Power considerations with 1466 lung cancer survivors, any percentage reported on the entire sample is accurate to within 2.6 with $95 \%$ confidence. Any mean reported on such a sample is accurate to within $5 \%$ times the standard deviation(SD) of the continuous variable's distribution, which is classified as a small effect size [39]. For example, it is known that our overall QOL scores that range from 0-100 have a standard deviation of roughly 16.7 points. This would mean that the mean QOL reported for this sample will be accurate to within 1 point on the $0-100$ point scale.
Covariates considered in this study can be broadly grouped into demographic (age, gender, race, comorbidities), social (employment status, marital status, years of education), smoking history (pack years, never, former, recent quitter, still smoking) disease-related (histology, stage, grade), and treatment-related (chemotherapy, radiation, surgery) characteristics. Smoking classification was assessed in several ways. First was pack years, defined as the number of packs of cigarettes smoked over time. For example, a participant who smoked one pack of cigarettes per day for 20 years, would have a 20 year pack history. Participants were also classified according to smoking status at the time they completed the survey packet: never smoker (less than 100 life time cigarettes), former smoker (quit more than 12 months), recent quitter (quit more than 30 days but less than 12 months), or current smoker (any tobacco usage in the past 30 days).

Model Building included Cox proportional hazards models (forward and backward stepping, saturated, and stepwise approaches) for relating exercise to survival while controlling for the covariates listed above. Cluster analysis was employed to identify correlated symptoms and treatment/disease status, thus reduce dimensionality of the numerous covariate influences that arose from the survival models.

\section{Results}

Demographics and clinical data are summarized in Table 1 for the 1466 lung cancer survivors comprising our sample. Survivors ranged in age from 18 to 93 years of age with an average age of 66 years ( $S D=11$ years). The sample was equally divided between the genders and $93 \%$ of the sample was Caucasian. Over $90 \%$ graduated high school and the majority was married (78 \%). Follow-up ranged as long as 9 years but averaged 3 years, and $35 \%$ of the possible study participants were dead at the time of study follow-up. Smoking behavior past or present was prevalent (83 \%) although $17 \%$ of the lung cancer survivors reported 
Table 2 Individual Baecke item overall distributions by physical activity level

\begin{tabular}{|c|c|c|c|c|}
\hline & Non-physically active $(N=331)$ & Physically active $(N=1135)$ & Total $(N=1466)$ & $p$ value \\
\hline Retired & & & & $<0.0001^{*}$ \\
\hline Missing & 68 & 153 & 221 & \\
\hline No & $56(21.3 \%)$ & $421(42.9 \%)$ & $477(38.3 \%)$ & \\
\hline Yes & 207 (78.7 \%) & $561(57.1 \%)$ & $768(61.7 \%)$ & \\
\hline Employed & & & & $<0.0001^{*}$ \\
\hline Missing & 4 & 6 & 10 & \\
\hline No & $285(87.2 \%)$ & $757(67.1 \%)$ & $1042(71.6 \%)$ & \\
\hline Yes & $42(12.8 \%)$ & $372(32.9 \%)$ & $414(28.4 \%)$ & \\
\hline At work - sit & & & & $0.0003^{*}$ \\
\hline Missing & 283 & 742 & 1025 & \\
\hline Never & $1(2.1 \%)$ & $24(6.1 \%)$ & $25(5.7 \%)$ & \\
\hline Seldom & $0(0 \%)$ & $57(14.5 \%)$ & $57(12.9 \%)$ & \\
\hline Sometimes & $7(14.6 \%)$ & $105(26.7 \%)$ & $112(25.4 \%)$ & \\
\hline Often & $27(56.3 \%)$ & $129(32.8 \%)$ & $156(35.4 \%)$ & \\
\hline Always/Very Often & $13(27.1 \%)$ & 78 (19.8\%) & $91(20.6 \%)$ & \\
\hline \multicolumn{5}{|l|}{ At work - stand } \\
\hline Missing & 289 & 745 & 1034 & \\
\hline Never & $14(33.3 \%)$ & 39 (10.0\%) & $53(12.3 \%)$ & \\
\hline Seldom & $28(66.7 \%)$ & $126(32.3 \%)$ & $154(35.6 \%)$ & \\
\hline Sometimes & $0(0 \%)$ & 140 (35.9 \%) & $140(32.4 \%)$ & \\
\hline Often & $0(0 \%)$ & 85 (21.8\%) & 85 (19.7 \%) & \\
\hline At work - walk & & & & $<0.0001^{*}$ \\
\hline Missing & 286 & 745 & 1031 & \\
\hline Never & 15 (33.3 \%) & $35(9.0 \%)$ & 50 (11.5\%) & \\
\hline Seldom & 30 (66.7 \%) & 117 (30.0 \%) & 147 (33.8\%) & \\
\hline Sometimes & $0(0 \%)$ & 166 (42.6 \%) & 166 (38.2 \%) & \\
\hline Often & $0(0 \%)$ & 72 (18.5 \%) & 72 (16.6 \%) & \\
\hline At work - lift & & & & $0.2175^{*}$ \\
\hline Missing & 314 & 860 & 1174 & \\
\hline Never & 12 (66.7 \%) & 138 (50.2 \%) & $150(51.4 \%)$ & \\
\hline Seldom & $5(33.3 \%)$ & 81 (29.5 \%) & 86 (29.5 \%) & \\
\hline Sometimes & $0(0 \%)$ & 42 (15.3\%) & 42 (14.4\%) & \\
\hline Often & $0(0 \%)$ & $14(5.1 \%)$ & $14(4.8 \%)$ & \\
\hline At work - sweat & & & & $0.0160^{*}$ \\
\hline Missing & 307 & 851 & 1158 & \\
\hline Never & 14 (58.3 \%) & 113 (39.8 \%) & $127(41.2 \%)$ & \\
\hline Seldom & 10 (41.7\%) & 95 (33.5 \%) & $105(34.1 \%)$ & \\
\hline Sometimes & $0(0 \%)$ & $60(21.1 \%)$ & 60 (19.5\%) & \\
\hline Often & $0(0 \%)$ & $16(5.6 \%)$ & 16 (5.2 \%) & \\
\hline After work - tired & & & & $0.0694^{*}$ \\
\hline Missing & 284 & 742 & 1026 & \\
\hline Never & $3(6.4 \%)$ & 37 (9.4 \%) & 40 (9.1\%) & \\
\hline Seldom & 12 (25.5 \%) & 155 (39.4 \%) & $167(38.0 \%)$ & \\
\hline
\end{tabular}


Table 2 Individual Baecke item overall distributions by physical activity level (Continued)

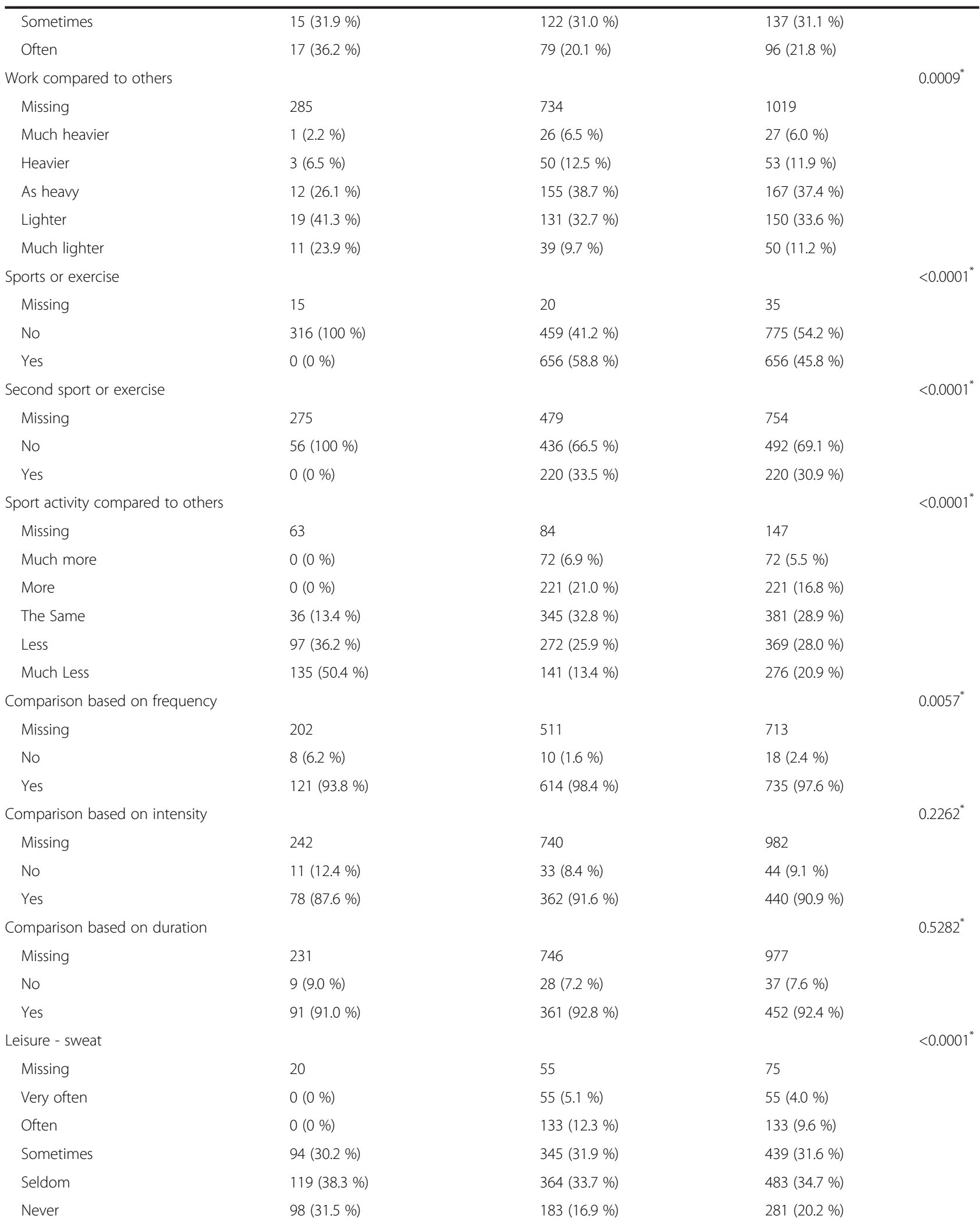


Table 2 Individual Baecke item overall distributions by physical activity level (Continued)

\begin{tabular}{|c|c|c|c|c|}
\hline \multicolumn{3}{|c|}{ Leisure - Yard or housework } & & \multirow[t]{2}{*}{$<0.0001^{*}$} \\
\hline Missing & 17 & 17 & 34 & \\
\hline Very often & $0(0 \%)$ & $355(31.8 \%)$ & $355(24.8 \%)$ & \\
\hline Often & $0(0 \%)$ & $433(38.7 \%)$ & $433(30.2 \%)$ & \\
\hline Sometimes & $176(56.1 \%)$ & $211(18.9 \%)$ & $387(27.0 \%)$ & \\
\hline Seldom & $60(19.1 \%)$ & $77(6.9 \%)$ & $137(9.6 \%)$ & \\
\hline Never & $78(24.8 \%)$ & $42(3.8 \%)$ & $120(8.4 \%)$ & \\
\hline \multicolumn{2}{|c|}{ Leisure - watch TV } & & & $<0.0001^{*}$ \\
\hline Missing & 9 & 23 & 32 & \\
\hline Very often & $118(36.6 \%)$ & $206(18.5 \%)$ & $324(22.6 \%)$ & \\
\hline Often & $96(29.8 \%)$ & $415(37.3 \%)$ & $511(35.6 \%)$ & \\
\hline Sometimes & $82(25.5 \%)$ & $381(34.3 \%)$ & $463(32.3 \%)$ & \\
\hline Seldom & $13(4.0 \%)$ & $97(8.7 \%)$ & $110(7.7 \%)$ & \\
\hline Never & $13(4.0 \%)$ & $13(1.2 \%)$ & $26(1.8 \%)$ & \\
\hline \multicolumn{2}{|l|}{ Leisure - walk } & & & $<0.0001^{*}$ \\
\hline Missing & 17 & 22 & 39 & \\
\hline Very often & 9 (2.9\%) & $166(14.9 \%)$ & $175(12.3 \%)$ & \\
\hline Often & $28(8.9 \%)$ & 355 (31.9 \%) & $383(26.8 \%)$ & \\
\hline Sometimes & $122(38.9 \%)$ & $390(35.0 \%)$ & $512(35.9 \%)$ & \\
\hline Seldom & 106 (33.8\%) & 166 (14.9\%) & $272(19.1 \%)$ & \\
\hline Never & 49 (15.6\%) & $36(3.2 \%)$ & $85(6.0 \%)$ & \\
\hline \multicolumn{2}{|l|}{ Leisure - bicycle } & & & $<0.0001^{*}$ \\
\hline Missing & 27 & 66 & 93 & \\
\hline Very often & $1(0.3 \%)$ & $24(2.2 \%)$ & $25(1.8 \%)$ & \\
\hline Often & $4(1.3 \%)$ & 55 (5.1\%) & $59(4.3 \%)$ & \\
\hline Sometimes & $14(4.6 \%)$ & 148 (13.8 \%) & $162(11.8 \%)$ & \\
\hline Seldom & 37 (12.2 \%) & 186 (17.4 \%) & $223(16.2 \%)$ & \\
\hline Never & $248(81.6 \%)$ & 656 (61.4 \%) & $904(65.8 \%)$ & \\
\hline \multicolumn{2}{|c|}{ Leisure - Walk/bike minutes per day } & & & $<0.0001^{* *}$ \\
\hline $\mathrm{N}$ & 171 & 695 & 866 & \\
\hline Mean (SD) & $6.9(15.1)$ & $18.7(32.7)$ & $16.3(30.4)$ & \\
\hline Median & 0.0 & 10.0 & 5.0 & \\
\hline Q1, Q3 & $0.0,10.0$ & $0.0,30.0$ & $0.0,30.0$ & \\
\hline Range & (0-120) & $(0-600)$ & $(0-600)$ & \\
\hline
\end{tabular}

"Chi-square test, ${ }^{* *}$ Wilcoxon

that they had never smoked. For those that smoked the average pack years was 47 years. Roughly half of the survivors had advanced stage disease at the time of observation. Treatment prevalence rates were 61, 54 , and $33 \%$ for surgery, chemotherapy and radiotherapy respectively.

Physical activity level of survivors was dichotomized as physically active or not physically active by the readiness to change scale as described above. The majority $(77 \%)$ of the 1466 patients who provided a physical activity classification (6 out of the original 1472 patients did not) reported themselves as being in the action stage for physical activity based on this classification. The individual item results for the Baecke activity questionnaire are given in Table 2 . Survivors who were physically active reported significantly different results for almost all of the individual Baecke items. Almost $62 \%$ of the patients were retired, while $28 \%$ identified themselves as being employed. Roughly $45 \%$ of patients reported they 
participated regularly in sports or exercise an average of $6 \mathrm{~h}$ per week. Roughly half of the survivors indicated that they thought they participated in sport activity less than others. Over three quarters of the survivors reported that they engaged in cycling on at least a semi-regular basis. Roughly $15 \%$ (208 out 1427) of patients changed their level of physical activity over time.

Co-morbidities and cancer stage impact on physical activity indicated that patients with co-morbidities were more likely to not be physically active versus those who did not have co-morbidities (23\% versus $18 \%$, $p=0.14$ respectively). Similarly, patients with early stage disease were more likely to be physically active than those with late stage disease $(83 \%$ versus $72 \%$, $p<.001$ respectively).

Lung cancer treatment impact on physical activity is provided in Table 3. Participants who were physically active were more likely to be surgical patients than receiving chemotherapy or radiation $(43,11$ and $11 \%$, respectively). Similarly, more of the surgical patients $(87 \%)$ were physically active than for the other treatments (73 \%) For survivors who had multiple treatments, $14 \%$ of patients changed in the degree of physical activity level after 1 year.

Lung cancer survivor-reported QOL indicated the benefits of physical activity in all domains (Table 4). Overall QOL and physical QOL differed by more than 15 points on a $0-100$ point scale, roughly equivalent to one standard deviation, a huge effect size. Emotional and mental well-being differed by roughly 9 points, larger than a clinically meaningful effect size of $50 \%$ times the standard deviation. Lung cancer survivors who were physically active also reported less pain frequency, pain severity, dry coughing, coughing with phlegm, SOB, and fatigue.

Physical activity by time until death analysis indicated that patients who were within 6 months of death less active than patients who were 6 months to a year, versus more than a year away from death $(72,76,78 \%$ respectively and $p=0.80$ ).
Disease recurrence rates were the same whether the patients reported being physically active $(81 \%)$ or not physically active (82\%) (Chi-square test $p=0.62)$. Overall survival however was profoundly different as seen in Fig. 1 with those who were physically active surviving an average of 4 more years than those who were not physically active (8.4 years versus 4.4 years respectively, logrank $p<0.0001)$. The impact of being physically active on survival was consistent across disease stage (early versus late, Fig. 2) and type of lung cancer (Non-Small Cell Lung Cancer (NSCLC) vs. Small Cell Lung Cancer (SCLC), Fig. 3). When covariates (age at diagnosis, gender, race, disease stage, treatment, smoking status, and pack years) were added to the survival analysis via a Cox regression model, the hazard ratio for non-physically active patients to physically active patients was 1.29 (Table 5, $95 \% \mathrm{CI}=1.00$ to 1.67, $p=0.05$ ).

Cluster analysis of the nine potentially important variables (Fig. 4) indicated that two clusters formed readily related to symptoms (pain, fatigue, cough, shortness of breath, physical active status) and to treatment/disease status (treatment type, disease stage, smoking status). Cluster analysis/logistic regression indicated that the first characteristic differentiating active patients from inactive patients was fatigue, followed by pain, treatment, age at diagnosis and smoking status. Collectively these five items accounted for $19 \%$ of the variance in physical activity.

\section{Discussion}

This large prospective epidemiological study of lung cancer survivors provides further support for the premise that being physical active is beneficial to both quality and quantity of life. Virtually all QOL domains studied indicated clinically meaningful advantages for lung cancer survivors reporting being physically active versus those who were not physically active.

These findings are consistent with previous literature in that the benefits of being active for lung cancer

Table 3 Treatment type by physical activity level

\begin{tabular}{llll}
\hline & Non-physically active $(N=331)$ & Physically active $(N=1135)$ & Total $(N=1466)$ \\
\hline Treatment & 12 & 27 & 39 \\
Missing & $90(6.3 \%)$ & $490(34.3 \%)$ & $580(40.6 \%)$ \\
Surgery alone & $75(5.3 \%)$ & $155(10.9 \%)$ & $230(16.1 \%)$ \\
Chemo or radio alone & $29(2.0 \%)$ & $121(8.5 \%)$ & $150(10.5 \%)$ \\
Surgery and chemo or radio & $67(4.7 \%)$ & $161(11.3 \%)$ & $228(16.0 \%)$ \\
Chemo plus radio & $58(4.1 \%)$ & $181(12.7 \%)$ & $239(16.8 \%)$ \\
Other & & & \\
\hline
\end{tabular}


Table 4 Quality of life by physical activity level

\begin{tabular}{|c|c|c|c|c|}
\hline & Non-physically active $(N=331)$ & Physically active $(N=1135)$ & Total $(N=1466)$ & $p$ value \\
\hline Emotional well being & & & & $<0.0001$ \\
\hline N & 299 & 1015 & 1314 & \\
\hline Mean (SD) & $69.3(22.1)$ & $77.8(19.4)$ & $75.9(20.3)$ & \\
\hline Deficiency $(<=50)$ & $92(30.8 \%)$ & $150(14.8)$ & & \\
\hline Physical well being & & & & $<0.0001$ \\
\hline N & 299 & 1015 & 1314 & \\
\hline Mean (SD) & $54.2(22.9)$ & $70.8(20.2)$ & $67.1(21.9)$ & \\
\hline Deficiency $(<=50)$ & $166(55.5 \%)$ & $229(22.6 \%)$ & & \\
\hline Mental well being & & & & $<0.0001$ \\
\hline N & 299 & 1016 & 1315 & \\
\hline Mean (SD) & $71.7(21.70)$ & $80.1(18.5)$ & $78.2(19.6)$ & \\
\hline Deficiency $(<=50)$ & $82(27.4 \%)$ & $120(11.8 \%)$ & & \\
\hline Overall QOL & & & & $<0.0001$ \\
\hline N & 299 & 1014 & 1313 & \\
\hline Mean (SD) & $59.3(23.3)$ & $75.6(18.8)$ & $71.9(21.1)$ & \\
\hline Deficiency $(<=50)$ & $140(46.2 \%)$ & $161(16.0 \%)$ & & \\
\hline Frequency of pain & & & & $<0.0001$ \\
\hline N & 296 & 1013 & 1309 & \\
\hline Mean (SD) & $57.0(30.5)$ & $67.4(29.1)$ & $65.0(29.7)$ & \\
\hline Deficiency $(<=50)$ & $145(49.0 \%)$ & $339(33.5 \%)$ & & \\
\hline Severity of pain & & & & $<0.0001$ \\
\hline N & 296 & 1014 & 1310 & \\
\hline Mean (SD) & $61.4(27.1)$ & $72.7(24.7)$ & $70.2(25.7)$ & \\
\hline Deficiency $(<=50)$ & $129(43.6 \%)$ & $258(25.4 \%)$ & & \\
\hline Frequency of dry coughing & & & & 0.0035 \\
\hline N & 299 & 1016 & 1315 & \\
\hline Mean (SD) & $67.0(27.3)$ & $71.7(27.2)$ & $70.6(27.3)$ & \\
\hline Deficiency $(<=50)$ & $96(32.1 \%)$ & $273(26.9 \%)$ & & \\
\hline Frequency of coughing with phlegm & & & & $<0.0001$ \\
\hline N & 297 & 1011 & 1308 & \\
\hline Mean (SD) & $67.3(29.4)$ & $75.6(26.8)$ & $73.7(27.6)$ & \\
\hline Deficiency $(<=50)$ & $102(34.3 \%)$ & $228(22.5 \%)$ & & \\
\hline Shortness of breath & & & & $<0.0001$ \\
\hline N & 299 & 1018 & 1317 & \\
\hline Mean (SD) & $46.9(27.7)$ & $59.5(27.4)$ & $56.6(28.0)$ & \\
\hline Deficiency $(<=50)$ & $191(63.9 \%)$ & $448(44.0 \%)$ & & \\
\hline Level of fatigue & & & & $<0.0001$ \\
\hline N & 299 & 1018 & 1317 & \\
\hline Mean (SD) & $39.6(23.1)$ & $53.9(24.3)$ & $50.7(24.8)$ & \\
\hline Deficiency $(<=50)$ & 227 (75.9 \%) & 555 (54.5 \%) & & \\
\hline
\end{tabular}




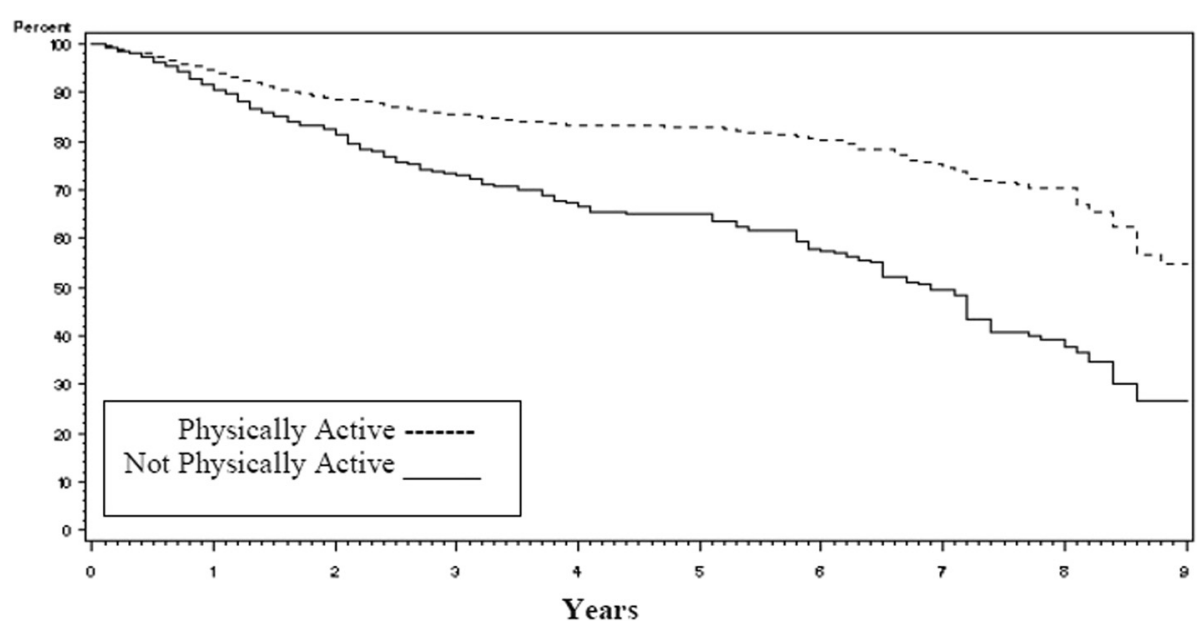

Fig. 1 Kaplan-Meier survival curves for lung cancer survivors by level of physical activity
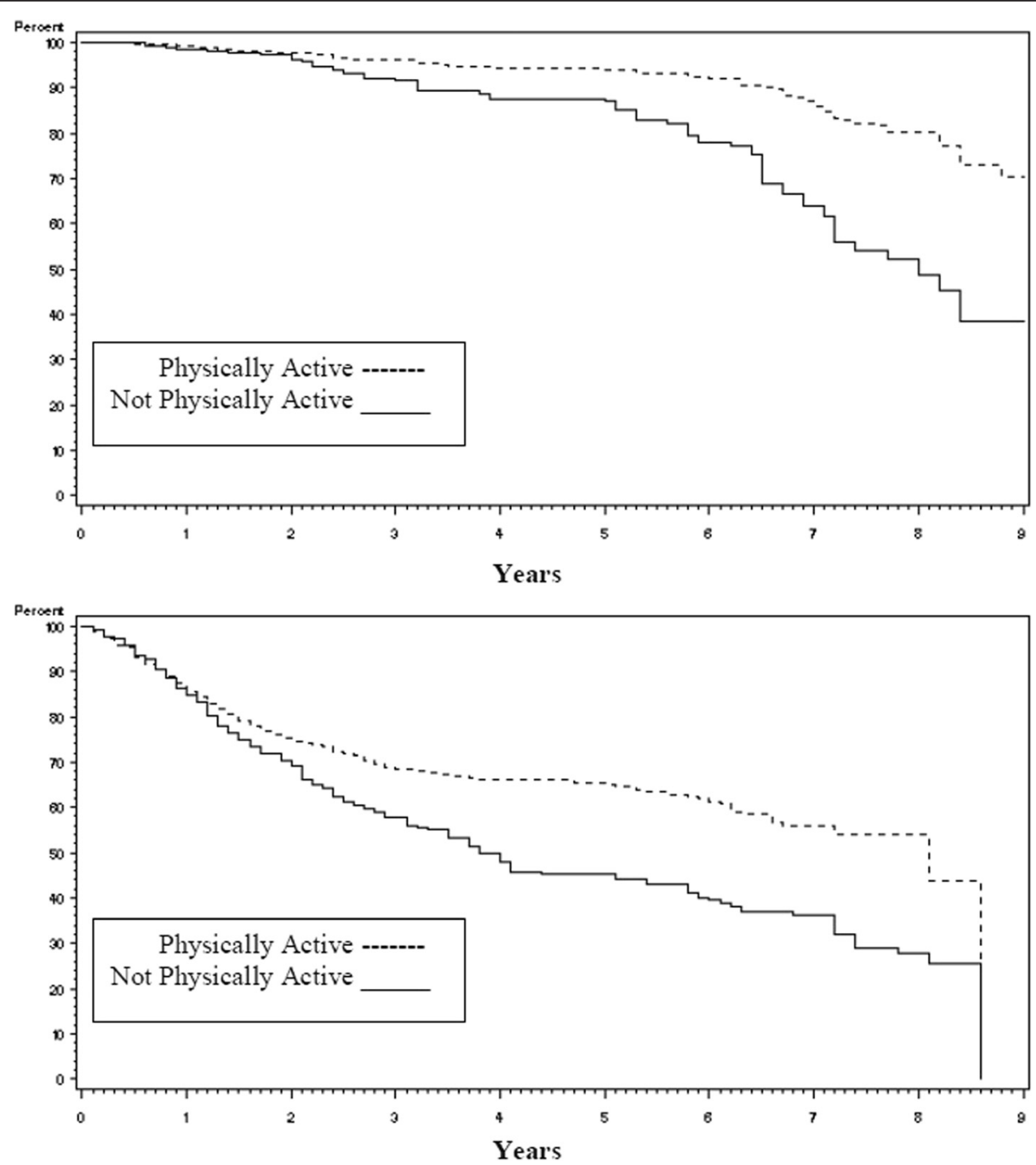

Fig. 2 Kaplan-Meier survival curves for lung cancer survivors by stage of disease (early vs late) 

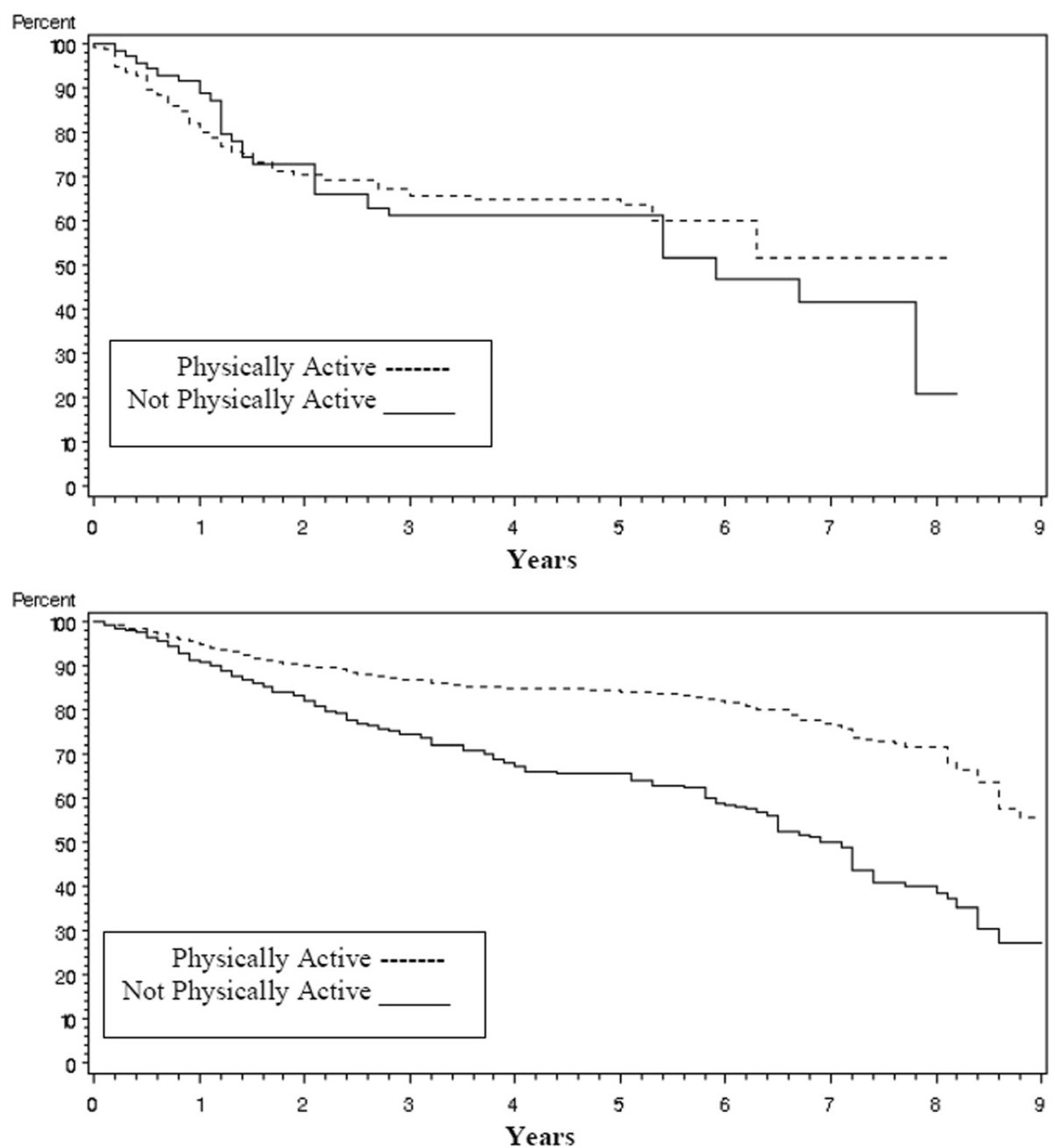

Fig. 3 Kaplan-Meier survival curves for lung cancer survivors by type of lung cancer (Non-Small Cell Lung Cancer(NSCLC) vs Small Cell Lung Cancer(SCLC))

survivors are similar to those for the general population. The differences were profound in terms of the effect size benefit for those who are physically active. Recent studies of the most prevalent and concerning symptoms among cancer patients indicate that similar to our patients, fatigue, pain and insomnia are major impacts on the QOL of lung cancer patient survivors. Smoking continues to be a profound indicator of well-being for cancer patients. The results are also consistent with our previous work on the prognostic power of overall QOL on the survival of lung cancer patients30 in that it highlights a natural linkage between physical activity, health promotion behavior, and QOL which together in turn contribute to the quality and quantity of survival in patients with lung cancer.

This report provides new information regarding the specific issues facing lung cancer survivors. Encouragingly, the majority of lung cancer survivors do remain physically active. The deficits observed however are specific to lung cancer and different from those expressed by breast cancer survivors for example. Further, this study identified that physical activity in general was related to the level of symptoms experienced and the type of treatments received. In particular, surgical patients can be expected to be more likely to be physically active because they are likely to be earlier stage and less ill than other patients.

This study has limitations in that it is an observational rather than a controlled experimental layout. There could be concomitant influences alongside the physical activity reporting that could account for the majority of the apparent impact. For example, performance status and stage of disease could play a role in determining if a person is physically active or not. This is unlikely the case in this study however, because even once these covariates had been included 
Table 5 Cox regression model

\begin{tabular}{|c|c|c|c|c|}
\hline Parameter & Hazard ratio & $95 \%$ hazard & & $P$ value \\
\hline Non physically active & 1.294 & 1.003 & 1.669 & 0.0472 \\
\hline Age at diagnosis & 1.019 & 1.007 & 1.031 & 0.0021 \\
\hline Female & 0.828 & 0.662 & 1.035 & 0.0976 \\
\hline Surgery alone & 0.414 & 0.283 & 0.606 & $<.0001$ \\
\hline Chemo or radio alone & 2.333 & 1.665 & 3.268 & $<.0001$ \\
\hline Surgery and chemo or radio & 0.728 & 0.468 & 1.134 & 0.1602 \\
\hline Chemo plus radio & 1.463 & 1.027 & 2.085 & 0.0353 \\
\hline Never smoker & 0.890 & 0.620 & 1.279 & 0.5292 \\
\hline Former smoker & 1.062 & 0.824 & 1.369 & 0.6418 \\
\hline Overall QOL & 0.992 & 0.987 & 0.998 & 0.0057 \\
\hline Fatigue & 0.992 & 0.985 & 0.998 & 0.0094 \\
\hline Coughing & 1.002 & 0.997 & 1.007 & 0.4913 \\
\hline Shortness of breath & 1.003 & 0.998 & 1.008 & 0.2170 \\
\hline Pain & 0.997 & 0.992 & 1.001 & 0.1594 \\
\hline Stage I & 0.329 & 0.226 & 0.479 & $<.0001$ \\
\hline Stage II & 0.405 & 0.250 & 0.656 & 0.0002 \\
\hline Stage III/Limited & 0.551 & 0.419 & 0.726 & $<.0001$ \\
\hline
\end{tabular}

in the survival model, the significance of the physical activity level remained.

Further, it is acknowledged that obtaining accurate measures of physical activity is challenging. In this study we encountered a major barrier in the quality of the data returned for the Baecke questionnaire. Presumably in previous validation studies, participants were given the questionnaire in the presence of study assistants who could help them answer the relatively complex and involved questions of the Baecke questionnaire. Nonetheless, we were able to analyze the individual items and saw that the results were amazingly consistent for all 16 questions. Future research is needed to make this challenging task easier for patients and scientists to obtain accurate and consistent estimates of physical activity, especially since the impact

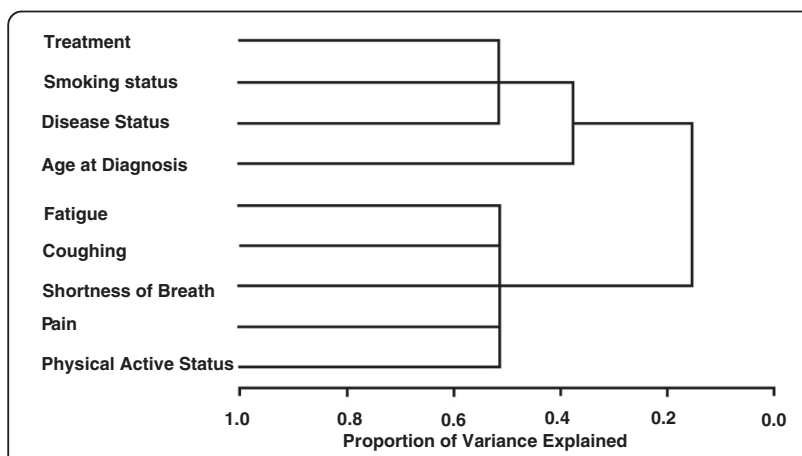

Fig. 4 Cluster dendogram for lung cancer survivors of physical activity has demonstrated to have potentially profound impact on patient well-being.

\section{Conclusion}

Some recent work described the ability to integrate objective measures in large cohort design, the future studies should employ objective measures of physical activity, such as the accelerometry [40, 41].

\section{Abbreviations}

LCSS: Lung Cancer Symptom Scale; NCCTG: North Central Cancer treatment Group; QOL: quality of life.

\section{Competing interests}

The authors declare that they have no competing interests.

\section{Authors' contributions}

CW and PY provided direct input into the design and execution of the study. JS and HL undertook statistical analysis and generated the results. JS drafted the manuscript and $A C, H L, M C, Y G$, and PY contributed to its editing. All authors read and approved the final manuscript.

\section{Acknowledgement}

This work was supported by research grants CA77118, CA80127, and CA84354 awarded to Dr. Ping Yang from the U.S. NIH and CA149950 awarded to Dr. Jeff Sloan.

\section{Funding sources}

This study has been funded by National Institutes of Health. Grant Numbers: R01-84354, R01-115857.

\section{Author details}

'Department of Health Sciences Research, 200 First St SW, Rochester, MN 55905, USA. ${ }^{2}$ Department of Physical Medicine and Rehabilitation, Rochester, USA. ${ }^{3}$ Department of Radiation Oncology, Rochester, USA. ${ }^{4}$ Department of Psychiatry and Psychology, Mayo Clinic, Rochester, MN 55905, USA. 


\section{Received: 28 August 2015 Accepted: 31 March 2016} Published online: 29 April 2016

\section{References}

1. Jones LW, Eves ND, Waner E, Joy AA. Exercise therapy across the lung cancer continuum. Curr Oncol Rep. 2009;11(4):255-62.

2. Betof AS, Dewhirst MW, Jones LW. Effects and potential mechanisms of exercise training on cancer progression: A translational perspective. Brain Behav Immun.2013 Mar; 30(0): S75-S87.

3. Jones LW, Demark-Wahnefried W. Diet, exercise, and complementary therapies after primary treatment for cancer. Lancet Oncol. 2006;7(12):1017-26.

4. Siegel R, Naishadham D, Jemal A. Cancer statistics, 2012. CA Cancer J Clin. 2012;62(1):10-29.

5. Jones LW. Physical activity and lung cancer survivorship. Recent Results Cancer Res. 2014;186:255-274.

6. Coups EJ, Park BJ, Feinstein MB, et al. Physical activity among lung cancer survivors: changes across the cancer trajectory and associations with quality of life. Cancer Epidemiol Biomarkers Prev. 2009;18(2):664-72.

7. Loewen GM, Watson D, Kohman L, et al. Preoperative exercise Vo2 measurement for lung resection candidates: results of Cancer and Leukemia Group B Protocol 9238. J Thorac Oncol. 2007;2(7):619-25.

8. Benzo R, Kelley GA, Recchi L, Hofman A, Sciurba F. Complications of lung resection and exercise capacity: a meta-analysis. Respir Med. 2007;101(8):1790-7.

9. Bobbio A, Chetta A, Ampollini L, et al. Preoperative pulmonary rehabilitation in patients undergoing lung resection for non-small cell lung cancer. Eur J Cardiothorac Surg. 2008:33(1):95-8.

10. Kasymjanova G, Correa JA, Kreisman $H$, et al. Prognostic value of the six-minute walk in advanced non-small cell lung cancer. J Thorac Oncol. 2009;4(5):602-7.

11. Jones LW, Peddle CJ, Eves ND, et al. Effects of presurgical exercise training on cardiorespiratory fitness among patients undergoing thoracic surgery for malignant lung lesions. Cancer. 2007;110(3):590-8.

12. Cesario A, Ferri L, Galetta D, et al. Pre-operative pulmonary rehabilitation and surgery for lung cancer. Lung Cancer. 2007;57(1):118-9.

13. Spruit MA, Janssen PP, Willemsen SC, Hochstenbag MM, Wouters EF Exercise capacity before and after an 8-week multidisciplinary inpatient rehabilitation program in lung cancer patients: a pilot study. Lung Cancer. 2006;52(2):257-60.

14. Temel JS, Greer JA, Goldberg S, et al. A structured exercise program for patients with advanced non-small cell lung cancer. J Thorac Oncol. 2009;4(5):595-601.

15. Cheville AL, Kollasch J, Vandenberg J, et al. A Home-Based Exercise Program to Improve Function, Fatigue, and Sleep Quality in Patients With Stage IV Lung and Colorectal Cancer: A Randomized Controlled Trial. J Pain Symptom Manage. 2013;45(5):811-21.

16. Clark MM, Novotny PJ, Patten CA, Rausch SM, Garces YI, Jatoi A, Sloan JA, Yang P. Motivational readiness for physical activity and quality of life in longterm lung cancer survivors. Lung Cancer. 2008;61(1):117-22. Epub 2008 Feb 19.

17. Yang P, Allen MS, Aubry MC, et al. Clinical Features of 5,628 Primary Lung Cancer Patients: Experience at Mayo Clinic from 1997-2003. Chest. 2005;128:452-62.

18. Hollen PJ, Gralla RJ, Kris MG, et al. Normative data and trends in quality of life from the Lung Cancer Symptom Scale (LCSS). Support Care Cancer. 1999; 7:140-8.

19. Hollen PJ, Gralla RJ, Kris MG, McCoy S, Donaldson GW, Moinpour CM. A comparison of visual analogue and numerical rating scale formats for the Lung Cancer Symptom Scale (LCSS): does format affect patient ratings of symptoms and quality of life? Qual Life Res. 2005;14(3):837-47.

20. Sloan JA. Applying QOL assessments: solutions for oncology clinical practice and research. Curr Prob Cancer. Part 1, 2005;29(6) and Part 2, 2006;30(6).

21. Huschka MM, Mandrekar SJ, Schaefer PL, Jett JR, Sloan JA. A pooled analysis of quality of life measures and adverse events data in north central cancer treatment group (NCCTG) lung cancer clinical trials. Cancer. 2007;109(4):787-95.

22. Buchanan DR, O'Mara AM, Kelaghan JW, Minasian LM. Quality-of-Life Assessment in the Symptom Management Trials of the National Cancer Institute-Supported Community Clinical Oncology Program. J Clin Oncol. 2005;23(3):591-8.
23. Giorgi F, Cellerino R, Gramazio A, Tummarello D, Menichetti ET, Giordani P, Antognoli S, Carle F, Piga A. Assessing quality of life in patients with cancer: a comparison of a visual-analogue and a categorical model. Am J Clin Oncol. 1996;19(4):394-9.

24. Ballatori E, Porzio G, Roila F, Ruggeri B, Mattei A, Cortesi E. Is there still a role for the uniscale assessment of quality of life? Tumori. 2007;93(1):78-81.

25. Sloan JA, Berk L, Roscoe J, Fisch MJ, Shaw EG, Wyatt G, Morrow GR, Dueck AC. National Cancer Institute. Integrating patient-reported outcomes into cancer symptom management clinical trials supported by the National Cancer Institute-sponsored clinical trials networks. J Clin Oncol. 2007:25(32):5070-7.

26. Locke DE, Decker PA, Sloan JA, Brown PD, Malec JF, Clark MM, Rummans TA, Ballman KV, Schaefer PL, Buckner JC. Validation of Single-Item Linear Analog Scale Assessment of Quality of Life in Neuro-Oncology Patients. J Pain Symptom Manage. 2007;34(6): 628-38.

27. Ginns $P$, Barrie $S$. Reliability of single-item ratings of quality in higher education: a replication. Psychol Rep. 2004;95(3 Pt 1):1023-30.

28. Zimmerman M, Ruggero CJ, et al. Developing brief scales for use in clinical practice: the reliability and validity of single-item self-report measures of depression symptom severity, psychosocial impairment due to depression, and quality of life. J Clin Psychiatry. 2006;67(10):1536-41.

29. Butt $Z$ et al. Use of a Single-Item Screening Tool to Detect Clinically Significant Fatigue, Pain, Distress, and Anorexia in Ambulatory Cancer Practice. J Pain Symptom Manag. 2008:35:20-30.

30. Jeff AS, Xinghua Z, et al. Relationship Between Deficits in Overall Quality of Life and Non-Small-Cell Lung Cancer Survival. J Clin Oncol. 2012;30(13):1498-504

31. Pols MA, Peeters PH, Bueno-De-Masquita HB, et al. Validity and repeatability of a modified Baecke questionnaire on physical activity. Int J Epidemiol. 1995;24:381-8.

32. JA Baecke JA, Burema J, Frijters JE. A short questionnaire for the measurement of habitual physical activity in epidemiological studies. Am J Clin Nutr. 1982;36:936-42.

33. Ono R, Hirata S, et al. Reliability and validity of the Baecke physical activity questionnaire in adult women with hip disorders. BMC Musculoskelet Disord. 2007;8:61.

34. Richardson MT, Ainsworth BE, et al. Ability of the atherosclerosis risk in communities (ARIC)/Baecke questionnaire to assess leisure-time physical activity. Int J Epidemiol. 1995;24:685-93. 15.

35. Van Baak MA, van Mil E, Astrup AV, Finer N, Van Gaal LF, Hilsted J, Kopelman PG, Rossner S, James WP, Saris WH, STORM Study Group. Leisuretime activity is an important determinant of long-term weight maintenance after weight loss in the Sibutramine Trial on Obesity Reduction and Maintenance (STORM trial). Am J Clin Nutr. 2003:78:209-14.

36. Nielens $H$, Lejeune TM, Lalaoui A, Squifflet JP, Pirson Y, Goffin E. Increase of physical activity level after successful renal transplantation: a 5 year followup study. Nephrol Dial Transplant. 2001;16:134-40.

37. Bonnefoy M, Normand S, Pachiaudi C, Lacour JR, Laville M, Kostka T. Simultaneous validation of ten physical activity questionnaires in older men: a doubly labeled water study. J Am GeriatrSoc. 2001;49:28-35.

38. Emmy MH, Evelyn MM, Evert GS, Petra HMP, Albertine JS. Validity of the Modified Baecke Questionnaire: comparison with energy expenditure according to the doubly labeled water method. Int J Behav Nutr Phys Act. 2008:5:30.

39. Cohen J. Statistical Power Analysis for the Behavioral Sciences. Hillsdale, New Jersey: Lawrence Erlbaum Associates; 1988.

40. -Min L, Eric JSH. Using accelerometers to measure physical activity in large-scale epidemiological studies: issues and challenges. Br J Sports Med. 2014;48:197-201.

41. Howard VJ, Rhodes JD, Mosher A, Hutto B, Stewart MS, Colabianchi N, Vena JE, Blair SN, Hooker SP. Obtaining Accelerometer Data in a National Cohort of Black and White Adults. Med Sci Sports Exerc. 2015;47(7):1531-7. 